\title{
DIDACTISMO, GÉNERO LITERARIO Y LECTOR EN GIRALDI CINZIO
}

\author{
Mireia Aldomà García \\ mireia.aldoma@gmail.com
}

$\mathrm{L}$

a recepción e imitación de los novellieri en España es una cuestión ampliamente estudiada en la historia de la literatura (Menéndez Pelayo 1961); en los últimos años (González 2011, Federici 2014) se ha señalado la necesidad de estudiar los paratextos y otros textos afines, empresa importante que quizás también permita revisar el tan manido tema de la honestidad de la novela del siglo XVI en Italia y en España. Suele darse por hecho, porque así lo manifiestan los autores en los prólogos, que, a mitad del siglo xvı, la novela italiana abandona el tema del amor lascivo a causa de la influencia de Trento y que las traducciones españolas aumentan esa honestidad. En 1590 se publican los Hecatommithi de Giraldi Cinzio traducidos al español bajo el nombre de Primera Parte de las Cien Novelas. Es una traducción parcial en la que se retocan algunas novelas y se abrevia el marco. La recepción de la obra en España puede considerarse un ejemplo, un tanto fracasado, de la adaptación de la novella italiana en la península (Aldomà 1993).

En este artículo nos proponemos abordar el amor lascivo en parte de la obra de Giraldi Cinzio, en concreto en un escrito teórico y en la Introducción de la Primera Parte de las Cien Novelas ${ }^{1}$. A lo largo del artículo confrontaremos el tema del amor en un discurso con la producción novelística para comprobar si los enunciados teóricos se aplican a los temas narrativos, configurando así un ejemplo de novela tridentina en Italia y en España, o bien se desvían de las supuestas exigencias contrarreformistas.

Suele estudiarse el Discorso intorno al comporre dei romanzi en relación con la producción novelística y dramática del autor (Beltrán 1996, Guerrieri Crocetti 1973), pero no suele tratarse el Discorso intorno a quello che si conviene ai giovani,

1 Las citas de la Primera parte de las Cien Novelas proceden de Aldomà (1998), y se añade la página del original de 1590. 
netamente moralizante, compuesto en 1565 en el mismo año que Giraldi publica los Hecatommithi. Desde otra perspectiva, la de los manuales, conviene abordar el Discorso intorno a quello che si conviene a giovane nobile e ben creato nel servire un gran principe, escrito en Mondovì en 1565, como un manual o un opúsculo de comportamiento del príncipe en la corte, uomo di corte, donde el autor, que conoce muy bien los textos de Castiglione (1528) y Della Casa (1558), aglutina en un breve tratado la esencia de las normas de comportamiento ${ }^{2}$. La obra de Castiglione se había convertido en un modelo lingüístico y cultural desde su publicación en el temprano xvi, y el manual de conducta El Galateo, mucho más simple, pretendía reglamentar la dorada medianía horaciana, el hombre mezzano, equilibrado y sagaz. Giraldi Cinzio, como su gran antecesor, Castiglione, adopta el diálogo como forma de expresión de sus ideas filosóficas, a saber, la forma más apta para discutir y comunicar problemas de toda naturaleza (Vian 2010).

En 1565 Giraldi Cinzio se hallaba en Mondoví, Piamonte, y no en su Ferrara habitual. Tras la polémica con Pigna, había dejado de estar al servicio de la casa de Este, para pasar a residir en la ciudad piamontesa desde 1563, llamado por el duque Emanuel Filiberto de Saboya. El mismo autor da cuenta de la premura con la que se ve forzado a escribir, sea o no un tópico literario, y de la insistencia de su hijo Lucio Olimpo para que redactara ese opúsculo. El Discorso se publica en 1569 en Pavía, ciudad en la que Giraldi enseñaba oratoria desde 1568.

En principio va dirigido a Pietro Battista Lomellini, noble de familia genovesa dedicado a las armas, pero el destinatario final es todo joven que tenga que servir a un señor, a un príncipe, y le indica cómo moverse en esos ámbitos. Estamos, por tanto, ante un sucinto manual de cortesanía, a regañadientes del mismo autor:

Io aveva deliberato, Illustre e molto Magnifico Signore mio, di non mandare più a Vostra Signoria Illustre il Discorso che già quattro anni m'indusse a comporre Lucio Olimpio mio figliuolo, ad instanza di lei, intorno alla creanza di nobil giovane che desiderasse di porsi al servigio di gran Principe. Perché mi pareva, e ragionevolmente, che essendo egli stato composto nel tempo ch'ella attendeva agli studi della filosofia morale, e che non si era ancora data, per la troppo giovane età, alle imprese delle armi, fusse cosa soverchia mandarglielo ora che, con quattro galee nobilissimamente guarnite, si è messa, con tanta riputazione e tanto animo, alle onorate imprese di mare, nelle quali ella le ha valorosamente usate, insieme con la possente armata del Serenissimo Re Filippo, Re veramente Cattolico, in servigio della Maestà divina e a confermazion della santissima religione nostra (Cinzio 1989: 3).

\footnotetext{
El texto puede leerse en Moretti (1989). Giraldi Cinzio l'uomo di corte, o bien on line en http://dante.di.unipi.it/ricerca/html/Giraldi-Uomo.html\#Giraldi-Uomo-div2-d0e273. Las citas del Discorso en el artículo proceden de Moretti. Nos referimos al Discorso entendiendo por tal la obra de 1565.
} 
Aunque hayan transcurrido cuatro años, el hijo sigue insistiendo en entregarle el discurso:

Ma, poscia che Lucio Olimpio, il qual fu prima cagione che vi ponessi mano, mi ha significato ch'ella lo desidera, e che perciò egli non le sarà ora men caro che se glielo avessi mandato in quella sua più tenera età, mi sono deliberato di offerirglielo tale quale egli allora mi cadde dalla penna, e di darlo in luce sotto il suo onorato nome, acciò ch'egli appresso lei, e appresso a qualunque altro che si porrà a leggerlo, sia testimonio del desiderio ch'io ho di sempre onorarla (1989: 4).

La larga experiencia de Giraldi en la corte de Hércules de Este durante dieciséis años es la mejor presentación para poder abordar el tema; el autor manifiesta que durante tres días ha abandonado sus quehaceres habituales para resumir en pocas páginas la esencia de las normas del servicio al señor:

Avendomi scritto, illustre signor Pierbattista, Lucio Olimpio mio figliuolo, che desiderate grandemente che io che 16 anni continui ho conversato alla corte de1l'illustrissimo ed eccellentissimo Signore, il Signore Ercole secondo da Este, Duca quarto di Ferrara, Signore di felicissima e onoratissima memoria, il quale fu esempio di tutte le rare virtù e singolari doti che si debbino ritrovare in un gran Principe, appresso il quale fui, per tutto quel corso d'anni, segretario vi riducessi in poche carte quello che devrebbe osservare e sprezzare e seguire e fuggire un nobile e virtuoso Giovane in servire un gran Principe, accioché grata gli fusse la sua servitù; e veggendo io la cosa essere di vie maggiore importanza che Lucio Olimpio non crede, me ne sono ito tacendo infino ad ora: parendomi, ch>essendo io già attempato andato al servigio di quel grande e onoratissimo Signore (peroché io era di 44 anni quando sua Eccellenza mi chiamò a sì onorato ufficio), poteva mal mostrare ad un giovane, coll'esempio mio, quale egli al servigio del suo Signore esser devesse, essendo io stato per l'addietro occupato piuttosto negli studi delle lettere e nel leggere pubblicamente, che avere atteso a' maneggi delle corti. Ma continuando pure Lucio Olimpio a sollecitarmi, per nome vostro, che di ciò scrivessi, vinto dalla frequenza delle sue lettere e dal desiderio che io ho di sodisfare a voi, illustre giovane, lasciata subito per questi tre giorni ogn'altra cosa, ho porta la mano alla penna e ho raccolto in breve Discorso quello che dagli scrittori antichi e dalla conversazione delle corti, per quel tempo che vi sono stato, ho osservato insino ad ora. E perché resti adempito il desiderio vostro, quello vi mando che in questo poco spazio di tempo mi è venuto alla mente [...] (1989: 7).

Se trata, por tanto, de un breve discurso, escrito a instancias del hijo Lucio, publicado cuatro años más tarde. La presencia en la corte estense por parte de Giraldi le autoriza plenamente a hablar de cómo servir al príncipe o cómo sobrevivir en una corte en la que debería triunfar la virtud, tal como reza el lema del frontispicio de Pavía, Virtus Vulnere Virescit. La percepción que Giraldi tiene del servicio al 
príncipe es definitivamente pesimista. Algunos estudiosos, como Moretti (1989), atribuyen ese rasgo a las experiencias personales de Giraldi, excluido de la corte estense y en litigio con su discípulo Pigna. Además de las causas biográficas, el pesimismo de la obra muestra la evolución desde el optimismo renacentista a la desilusión humana, propia del venidero pesimismo barroco, recorridos del ideal cortesano señalados por Asor Rosa (1974) y Mazzacurati (1980).

El Discorso de Giraldi entronca, pues, con la tradición de los manuales de cortesanía y, a la vez, con la misma obra giraldiana, tanto con las novelas presentes en los Hecatommithi como con los Diálogos de la vida civil, que comparten el amargo sabor de la desconfianza. A pesar de que los Dialoghi fueran excluidos de la obra en ediciones posteriores o traducidos independientemente en francés y en inglés (Fenoglio 2014, Gorris 2005, Romera 1997), la obra giraldiana solo puede entenderse en el seno de un ambicioso proyecto enciclopédico (Bruscagli 2013) ${ }^{3}$.

El autor destaca al inicio que el aspirante a la vida cortesana encontrará numerosas dificultades en el camino, en medio de esa enmarañada sociedad que adula al señor y, para ejemplificarlo, acude al mito de Momo, personificación del sarcasmo y del mal, que aconseja sembrar la discordia en la tierra. Los cortesanos son, en 1565, los nuevos Momos en pos del mal ajeno:

\begin{abstract}
Venendo adunque a quello che io conosco essere desiderato da voi, dico che come il servire a gran Principe è di riputazione e di utile a gentiluomo ben nato e di nobile creanza (come oggidì si dice), quando il suo servire riesce grato, così è cosa più malagevole ch'altri non crede il darsi a ciò sì per la varietà delle nature degli uomini, le quali rade volte si affrontano ad esser simili, sì anche per la copia degli impedimenti che si ritrovano nelle corti, postivi da uomini maligni, da invidiosi, da adulatori, da morditori, che quasi nuovi Momi stanno sempre ad aspettare attentissimamente se loro si offerisce cosa alcuna al danno altrui. Né pure si pongono a riprendere $\mathrm{i}$ vizi, ma non mancano anche di dare quel maggior biasimo alla virtù che possono, o per scemare o per spegnere in tutto la riputazione di chi col bene operare la si ha acquistata, o cerca di acquistarlasi; e il costor numero si ritrova assai grande nelle corti (Cinzio 1989: 10).
\end{abstract}

Los malvados, prosigue Cinzio, recogiendo la fábula antigua, se han esparcido por el mundo:

Le quali poscia, accoppiatesi coll'odio e col livore, in poco ispazio di tempo produssero tanti altri figliuoli e nipoti, che si sparse in ogni parte della terra questa

\footnotetext{
Gli Ecatommiti furono dunque pensati non soltanto come un novelliere a la Boccaccio, ma come un novelliere alla Boccaccio più libro di lettere più trattatistica del comportamento più minicanzoniere più repertorio tematico: un testo saturo e letteralmente 'prolisso', stratificato, ansioso di accumulare in un' unica compagine i risultati più illustri di una tradizione narrativa ormai consolidata (Bruscagli 2013: 6).
} 
mala progenie; in guisa che non vi è, non dirò regione o città, ma casa alcuna privata nella quale non sia entrata questa pestilenza (1989: 11).

especialmente por las cortes, donde se han convertido en escollos en el mar de nuestra vida:

Ma poiché noi veggiamo che altrimente è avenuto, e che spesse fiate questi malvagi, per simolar bontà, hanno più facili gli orecchi de' maggiori, egli è sommamente da avvertire che nelle corti costoro, coprendo colla simolazione e con buon viso il loro mal animo, si oppongono di continuo a coloro che conoscono potere ascendere, per lo mezzo di fedele e virtuosa servitù, a qualche grado appresso il Signor loro, ed è questa pessima sorte di uomini come un mortal morbo fra corpi sani. E si possono anche chiamare acconciamente questi tali scogli, posti nel mar di questa vita, i quali, per starsi nascosi sotto quete onde, con tanta malagevolezza si possono schivare, che spesso spesso altri si pensa di battere sicuro camino e, solcando disavedutamente queste onde, percuote in essi e vi fa naufragio (1989: 11).

El naufragio no es otra cosa que el fracaso en los empeños cortesanos, asimilable a los vaivenes de la vida o rueda de la fortuna que llevan al servidor a caer en desgracia, como el mismo Giraldi ha sufrido en sus carnes:

massimamente nelle corti, che coloro ch'erano la vita e l'anima de' Signori, o per sdegno che prendono molte fiate per capriccio loro, o per mala relazione fatta contro il servitore da coloro che sono gli occhi e le orecchie de' Signori, quantunque virtuoso e fedele, o per altra cagione ben leggera, divengono loro in un momento in odio, e perdono in un punto quello che con molto tempo, con amorevolezza, con fede, con diligenza, con innumerabili fatiche e spese incredibili si avevano acquistato. E spesso, per lo dispiacere che ne sente il servitore, incorre egli in infermità incurabile, e vi lascia la vita: della qual cosa se ne veggono tali esempi di giorno in giorno, che se ne hanno vie più chiare le prove che non bisognerebbe (1989: 12).

Este preámbulo a la verdadera sustancia del discurso dista mucho del ambiente de concordia, a pesar de la huida, del que disfruta el grupo de cortesanos en su viaje hacia Marsella:

Agradó tanto a la mayor parte de los circunstantes lo dicho que todos los mancebos y las mugeres moças començaron con mucha instancia a rogar a los más ancianos que habían determinado quedarse a morir en Roma que no lo hiziesen. Los cuales, vencidos así de sus ruegos, como de las razones de Fabio, conformándose con la voluntad de los demás, determinaron ir fuera de Roma, y porque en los lugares comarcanos estaban las cosas en peor término que en las mesma ciudad, determinaron dexar de todo punto el romano suelo, y a Italia, y partirse a Marsella, que en otro tiempo fue arnés de romanos, y estarse allí hasta tanto que los negocios de 
su patria viniesen a mejor estado. Y así, dando luego parte de esta deliberación al señor de la casa, él gustó en gran manera de ello, y los proveyó de dos grandes y bien adereçadas naves, que estaban aprestadas en Civitavieja, donde un viernes por la mañana hizieron llevar todo cuanto tenían, y dándoles el mismo señor quien los guiase, para más seguridad de las personas y hazienda, poco después se partieron todos, por llegar a tiempo de embarcarse el domingo de mañana y, encomendándose a Dios, tomar de la insigne Marsella la derrota (Cinzio 1998: 23, f. 5v).

La maldad implícita en la corte, según el Discorso, no parece hallarse presente en el grupo, que tiene que abandonar su Roma natal por las desgracias acaecidas.

Los mismos personajes que partieron de Roma, al llegar a Génova tienen que buscar refugio por un temporal y, mientras los jóvenes son invitados a una batida de caza, los ancianos Fabio y Lelio se disponen conversar en presencia de un joven. La conversación no girará en torno a las novelas sino que se centrará en temas más graves, propios de su edad y de la circunstancia. En los Dialoghi della Vita Civile, considerados por los críticos como eje central de la obra de los Hecatommithi, se nos presenta la respuesta a cómo vivir la existencia (Maestri 1975; Patrizi 1991). Fabio, Lelio y Torquato, otro venerable anciano, junto al joven Gianettino Doria, se disponen a tratar temas serios despreciando el ajedrez y el novelar, aceptado en una situación extrema como la del barco, pero no en la ciudad. El joven solicita a los mayores experimentados una imagen de vida, un modelo del cual los jóvenes puedan aprender ${ }^{4}$.

En el primer diálogo, las explicaciones se centran en la edad infantil y su educación, en el segundo, en la edad juvenil y en el tercero, en la edad adulta. En el presente trabajo casi todas las alusiones serán al segundo diálogo, ya que el autor parece haber extraído las ideas del Discorso de las ampliamente desarrolladas en los Dialoghi.

El segundo diálogo se inicia con el discurso de Lelio en el que expone, siempre siguiendo a Aristóteles, los apetitos exagerados del joven, de naturaleza apasionada, en la que la libido aumenta sus deseos desordenados (Villari 2012: II, 1048), para proseguir con el proceso de aprendizaje del joven y sus virtudes, mientras que el tercero se consagra a la formación del hombre maduro. Vistos, pues, los tres diálogos como etapas de la vida humana, se entenderá que las ideas del Discorso procedan del segundo diálogo, consagrado a la juventud, aunque esté salpicado con otras de los restantes textos.

Volviendo al Discorso, tras las advertencias al joven candidato, Giraldi prosigue con las virtudes o condiciones del muchacho; así, mientras en los Dialoghi las virtudes aparecían bajo el paraguas protector de Platón, Aristóteles y otras autoridades, siempre enmarcadas en un ámbito teórico, en el Discorso, alejado de las especulaciones, plantea temas prácticos y útiles para el joven.

$4 \quad$ Las citas de los Dialoghi proceden de Villari (2012). 
La primera y fundamental cualidad es la bondad, la dabenagine giraldiana que, aunque actualmente la tomaríamos por ingenuidad, en ese momento era un término que no presentaba las connotaciones negativas actuales, y que se acercaría a la honradez, a la gallardía y a la honestidad:

E bisogna che si proponga, sopra tutte le cose, una eccellente dabenagine (siami lecito così dire), dalla quale non si diparta mai, ma l'abbia sempre per principal duce in tutte le sue azioni, perché senza essa tutto quello ch'egli facesse non sarebbe altro che pestar acqua nel mortaio. E posto che sia comune opinione che in alcune corti si ritrovino più mali uomini che buoni, e in alquante sia forse così in fatto, $\mathrm{e}$ si vegga spessissime volte che a questi si diano le dignità e gli onori di maggiore importanza (per sapere essi, con simolate maniere di fede, di pietà, d'integrità d'animo, proporre utilità dannose al publico bene e di gran frutto al Signore, che punto non curi altro che il suo comodo, avengane quanto avenir ne puote danno a' popoli suoi), dee nondimeno per ogni modo guardarsi il Giovane di non essere annoverato fra quelli ... (Cinzio 1989: 13-14).

La llamada a la bondad se refuerza frente a los cortesanos que actúan como Arístipo, famoso por adular a los reyes para conseguir su provecho ${ }^{5}$ :

Ho conosciuti io alcuni che, quasi nuovi Aristippi, si sono esposti nelle corti ad ogni scherno e ad ogni sozza opera per divenir grandi; e hanno fatto quello che veggiamo fare alle meretrici, le quali, poi che si hanno gittata la vergogna dopo le spalle, hanno conosciuto che il mostrarsi schife e vergognose non è loro di utile, ma che quanto più si scuoprono lascive e senza onesto rossore, tanto vien loro utile maggiore, e tanto sono a' lascivi loro amatori più care. Laonde questi tali, siansi in qual grado e in quante ricchezze essere si voglino, non sono degni di maggior riputazione appresso gli uomini da bene, che si siano queste disoneste donne (ancora che, ornate d'oro e di gemme, pomposamente vestite compariscano) appo le onestissime, benché queste in demesso e in non pomposo abito ma onestissimo, si scoprano (1989: 15).

Los peligros de la adulación habían cobrado una especial relevancia en el segundo diálogo:

E credono molto più a quelli che gli lusingano, lodando tutto quello che fanno, che a coloro che gli riprendono delle cose sconce e mostran loro la via della virtù col dire la verità. E questa cosa è la peggiore che a giovane avenir possa, e spezialmente a' principi giovani, a' quali sono tuttavia gli adulatori intorno (Cinzio 2012: 1051).

\footnotetext{
5 Aristipo, filósofo, es mostrado como ejemplo de adulación por Diógenes Laercio. Ver http:// www.e-torredebabel.com/Biblioteca/Diogenes-Laercio/Vida-Filosofos-Ilustres-Aristipo.html
} 
En el Discorso hallamos la primera alusión a las meretrices en el texto: en el fragmento citado, el autor compara a los cortesanos que actúan mal con las prostitutas que con su lascivia y deshonestidad acrecientan su valor y su provecho. Coinciden el Discorso y las Novelas en los términos empleados al tratar a las meretrices: lobas, Caribdis, monstruos, arpías (Villari 2012: XVIII):

cuya insaciable cobdicia y desenfrenado apetito son de los sabios escritores llamadas no menos que hambrientos lobos, poço sin suelo, espantosa Caribdis, robadoras Harpías (Cinzio 1998: 55, f. 25r).

No veis bien, Flaminio —respondió Fabio-, lo que dentro destos monstros es necesario que se vea, porque es menester que tenga el hombre la vista del lobo cerval para penetrar la corteza con que se cubren para engaños. Y de aquí vino que yendo los días pasados un gentilhombre, de suyo alegre y regozijado, aunque tenía lo más vivido, a visitar a una de estas hambrientas lobas, no más de por burlarse de ella, y saliéndole a recebir con los braços abiertos mostrando querer besarle en el rostro (1998: 55, f. 25r).

Nacen, Flaminio, de semejantes mugeres, fuera de los tormentos y dolores que causan, muchas y graves enemistades, sangrientas guerras, certísima pérdida de hazienda, de honra y de entendimiento, inevitables muertes, y, para dezirlo en breve, la perdición de las almas y de los cuerpos de aquellos que, amándolas, se aborrecen a sí mesmos y se pierden a sí proprios por buscarlas; las cuales en el coraçón les derraman el veneno que basta a privarlos de esta y de la otra vida. Porque así como el verdadero amor conserva aquello que posee, así el falso y deshonesto destruye y acaba a los desdichados que miserablemente tiene forçados y presos (1998: 60, f. 28r).

En el Discorso, del tema de la maldad el autor pasa a tratar en distintos apartados la edad del señor, la fidelidad que debe guardarse para llegar, obviando algunas cualidades, a la propuesta del modelo de los mayores:

Propostesi adunque queste cose in generale e altre simili, che troppo lunghe fora il volerle raccontar tutte, si porrà il nostro Giovane a quella maniera di servire alla quale egli si avrà conosciuto atto, e l'avrà ottenuta dal Signore; e vi userà quella diligenza, e quella destrezza e attillatura che converrà a ciò, pigliando nondimeno l`esempio da coloro che più antichi saranno e, prima di lui, a quello ufficio si saran dati, esaranno riusciti in loda appresso il Principe. Ché non si dee presumere il Giovane, per ingegnoso e per aveduto ch'egli si sia, di potere così di primo colpo essere da sé tale quali sono diventati coloro che per molto tempo e con lungo uso hanno quest'ufficio esercitato (1989: 19).

La importancia del consejo de los mayores queda patente en las novelas, donde la brigada acude a Fabio en pos de sabiduría aunque también con sutil ironía: 
No solo convenimos en ello - respondieron todos-, sino que os suplicamos, Fabio, que lo hagáis, por estar ciertos que no podréis dezir cosa de que no saquemos particular gusto y provecho (1998: 56, f. 25v).

A propósito de la manera de servir o estar en la corte, Giraldi expone un catálogo de justo medio, como Della Casa, ya que propugna el mostrarse alegre y festivo sin caer en la arrogancia, sin vanagloriarse de sus dichos y hazañas, omitiendo acciones indignas y juegos tontos, adornado siempre con modestia y gentil ironía:

Il nostro Giovane, adunque, si starà fra' termini della modestia, e ancora ch'egli si conosca degno di loda e si senta, per la sua virtù, lodare, non si devrà nondimeno insuperbire, ma riceverà quelle lodi con tal temperamento che ciò venga piuttosto dalla benevolenza di chi lo loda che dalle qualità sue, ovvero mostrerà di essere tanto più tenuto a chi gli dà loda, quanto egli conosce le lodi maggiori di ogni suo merito. E questa cortese maniera, che si può acconciamente addimandare una gentile ironia - nella quale scrivono gli antichi che fu maraviglioso Socrate - farà piú comparere la virtù sua che s'egli si scoprisse (Cinzio 1989: 24).

En lo que respecta a la preparación física del joven, aparecen los ejercicios habituales de un caballero: cabalgar, el juego de la pelota, el baile en ocasiones indicadas, la caza, entre los importantes, hay que destacar asimismo la prohibición de los duelos y otros juegos mortales, vetados por el Concilio de Trento. Temas todos ellos ampliamente tratados en los Dialoghi ${ }^{6}$.

Ma perché di ciò ho ragionato pienamente altrove, dirò solo che dee avere il popolo fedele grandissima obligazione a que' saggi e santi uomini c'hanno nel Concilio di Trento ordinato provisioni sotto Pio quarto pontefice massimo, colle quali hanno cercato di levare questa abominevole usanza, considerando essere vero quello che disse Aristotile: che per l'onesto si deono fare le battaglie, non per crudeltà; ch>altro che crudeltà non si dee chiamare simile sorte di battaglia introdotta per vendetta d'ingiuria privata, quantunque gli autori che di ciò favellano cerchino di condurre questa crudeltà a mantenimento dell'onesto, dal quale ella è lontanissima. Hanno non pure interdetta, ma del tutto scacciata dal mondo questa spezie di battaglia crudelissima ed inumana, e piuttosto infame che no, nonché conservatrice dell'onore, come dicono gli autori di questa mal usanza (1989: 34).

En las novelas, la brigada o grupo en su situación de huida no puede experimentar ese serie de ejercicios hasta que llega a Génova. Es durante la estancia en la ciudad a causa de un temporal cuando los jóvenes pueden divertirse con la caza mientras los viejos se apartan para filosofar. Las alusiones a las actividades

${ }_{6} \quad$ El duelo aparece en el primer diálogo, mientras que la gimnasia, la hípica, la música y otros, en el segundo (Villari 2012: II, 1092-1093). 
formativas y de ocio propias de los nobles en una situación habitual aparecen recogidas en los Dialoghi. De ellos extrae Giraldi las notas para el apartado que se ocupa de la formación y del ocio del joven cortesano. Frente a la síntesis de letras y pintura del Discorso en la parte V, en los Dialoghi se explayaba sobre el proceso de formación en las letras. El ocio de los nobles constituye el tema del apartado VII del Discorso.

Los juegos honestos, el ajedrez, la música, la diversión con los demás sin caer en la pesadez o aburrimiento son, a nuestro entender, tópicos cortesanos que se repiten en numerosos manuales. En las novelas, mientras dura el viaje en barco, los varones, apartados de los estudios y del ocio habitual, se disponen a tratar temas agradables, de gusto para los oyentes:

Si va a dezir verdad, señores, no sé ya qué hagamos, pues veo que el tiempo que solíamos gastar en danças, justas y torneos, y caça cuando dexábamos por algunos días la pesadumbre de los estudios para tomar algún alivio, le habemos de pasar ahora sobre el borde de la nave como captivos, porque, según veo, no hay cosa en nosotros que al presente pueda hazer con libertad su oficio sino los ojos y la lengua. Y de los ojos nos puede venir muy poco gusto, pues no vemos fuera del navío en que estamos sin cielo y agua, así que solo de la lengua podemos tener algún alivio. Por lo cual me parecía [7r] bien, si a todos les parece, que se gastase el tiempo que hay de aquí a la noche en tratar de alguna materia agradable y que sea igualmente de gusto para los oyentes (Cinzio 1998: 25, f. 7r) ${ }^{7}$.

En cambio, en Génova, al no estar ya en el barco, Fabio rehúye jugar al ajedrez, por considerarlo demasiado ocioso, así como a contar historias, prefiriendo los temas importantes que darán pie a los Dialoghi.

Entre las maneras de entretenerse el joven se alza el de motear, entendidos los motes como diversión cortesana:

Sarà, oltre a ciò, secondo il bisogno e come porterà la occasione, festevole e ridente, usando qualche motto vivo e grazioso, così in toccare altri civilmente come in ritoccare chi toccasse lui, guardandosi però sempre di non usar parola che morda troppo sul vivo: ché, come il motteggiare gentilmente e con leggiadria è cosa gratissima, così chi lascia il freno alla lingua od agguzza i denti più che non conviene a dar di morso, si acquista odio con non poco biasimo. E, nel ribattere cosa detta da grand'uomo a persona minore, dee spirito gentile molto accortamente mostrare di avere conosciuto il colpo e usare tal arte nel ribatterlo che, ancora che entri alquanto la percossa, non faccia nondimeno palese piaga (1989: 52).

7 La cautividad les restringe sus aficiones puesto que con los ojos solo pueden contemplar el mar; les queda la lengua, la oralidad, para tener algún deleite, por lo que deciden tratar durante la tarde alguna materia agradable para el grupo.

Edad de Oro, XXXIII (2014), pp. 87-107, ISSN: 0212-0429 
Motes agudos e ironías, que sí afloran en la brigada de los fugitivos romanos, entre los que destaca Poncio, especialmente cuando la composición de la brigada es exclusivamente masculina. La presencia de mujeres restringe la libertad de los cortesanos. Giraldi lo subraya en el Discorso:

E, nello scherzare co' motti, si dee sopra ogni cosa guardare il Giovane da parole sconcie e disoneste, e spezialmente avanti a gentildonne, il pregio delle quali è la modestia e l'onestà. E, ancora che la donna toccasse alquanto sul vivo il Giovane, egli dee nondimeno piuttosto concedere graziosamente quella licenza alla donna, ch'egli voglia fare arrossir lei col rimorderla licenziosamente (1989: 54).

En la Primera parte de las Cien Novelas, la presencia femenina altera también la libertad de la conversación. El primer día, el grupo que se aparta está compuesto solamente por hombres, mientras las mujeres se quedan en otra barca. ¿Simple casualidad? No: en aras de una mayor libertad temática, el grupo se aleja:

Pasaron breve tiempo de la semana en varios juegos y diversos razonamientos hasta tanto que, llegada la hora de mediodía y puestas las mesas, se sentaron a comer y, después que hubieron comido, ordenaron de en-[6v]tretenerse unos en un ejercicio y otros en otro, puesto que algunos inclinando sobre la mano la mejilla, se entregaron al sabroso sueño. Mas Poncio, Aulo, Máximo, Flaminio, Quinto, Sempronio, Curcio, Flabio y Lulio, que eran los más moços, viéndose en la nave entre algunos viejos graves, entre algunas ancianas y venerables dueñas, y entre otras mugeres moças así casadas como viudas, todas nobles y muy honestas, considerando que la gravedad de los varones, las severidad de las matronas y la honestidad, aunque moças, de las casadas y viudas, les quitaba libertad que en cosas de gusto y pasatiempo es propia de los hombres en la juventud, fingieron querer darles lugar para que descansasen. Se pasaron a la otra nave, llevando consigo a Fabio, el cual, aunque por su edad fuese grave y de maduro juizio, era tan agradable a la juventud como los mesmos mancebos. Pues cuando ya les pareció que estaban en libertad, siendo no menos regozijados que discretos, començaron a reír unos con otros y a ordenar gustosos y agradables juegos, procurando con varias fuentes de regozijo no sentir tanto la pesadumbre de la nave (Cinzio 1998: 24, f. 6v).

La naturaleza del grupo, exclusivamente masculino, es una de las razones que permite introducir las novelas sobre el amor deshonesto; razón importante pero no la única. En la Introducción, escrita con posterioridad al núcleo primitivo de novelas, el grupo masculino propone un tema, en este caso el amor, partiendo de una questio finita:

Y haziendo aquí una breve pausa, prosiguió diziendo: «El sujeto en que hoy se ha de hablar quiero, Fabio, que sea de Amor y que nos deis a entender de qué modo 
puede hallarse en él quietud y sosiego. Mirad, pues, si espaciándoos por tan florido campo como el del Amor, podréis, a imitación de la culebra, desnudaros el cuero antiguo y revestiros de la verde edad que ya de vos se ha ausentado» (1998: 27, f. 8r).

El amor es, por tanto, uno de los primeros temas que se debaten en la obra, especialmente en el marco introductorio, donde las disquisiciones amorosas adquieren un elevado tono filosófico al repetir las teorías neoplatónicas del amor expuestas, entre otros, por Bembo en los Asolani, tales como su tipología y características (Pozzi 1980) ${ }^{8}$.

Si en el debate se discute sobre una de las tendencias amorosas del siglo xvi, el amor neoplatónico, en los ejemplos, por el contrario, se nos presenta la otra cara, el amor lascivo, de modo que los ejemplos prácticos reclamados por los personajes se oponen aparentemente a las teorías enunciadas. Los personajes exigen una respuesta comprensible a la questio finita planteada sobre el amor, distinta a la propuesta en los numerosos tratados de la época, a los que tildan de quimeras. Flaminio solicita abandonar el aspecto idealizado del amor y centrarse en el mundo terrenal: una vez más el joven plantea una pregunta al anciano, el maestro, para que este responda con ejemplos prácticos al modo de la questio:

Quiero -dixo entonces Flaminio- que se dexen a una parte las contemplaciones y subtilezas que dezís que hay acerca del Amor, para mayores philósophos, para más subtiles ingenios y para mejor ocasión, y que estrechando su amplitud, de aquel Amor se trate que conviene a nuestros años y sugeta nuestros sentidos, y en quien mientras vivimos cada día y a cada paso tropezamos. Y así trayendo vos el Amor de las cosas divinas a las humanas, haréis en esta parte lo que hizo Sócrates de la Philosophía, que de pura contemplación que era de cosas divinas y eternas, la reduxo a vida civil y a costumbres humanas... Y tampoco consiento que habléis con el término que han hablado muchos, los cuales a mi parecer no se acuerdan si son humanos, pues quieren que solo con la vista, con el oído y con el entendimiento se deba gozar la belleza que se ama y no haya de buscarse más desto..., dexando que los philósophos se sustenten de las chimeras que vanamente fingen (Cinzio 1998: 28 ff. 8v-9r).

La importancia del amor en la vida del joven aparece también en el Discorso, donde el autor advierte de la necesidad de enamorarse, así como de los peligros de perder el cerebro, como recordaba el propio padre de Giraldi. La cuestión principal se plantea con el objeto del deseo, con la elección equivocada de la mujer,

8 Junto a los Asolani de Bembo y los Diálogos de Amor de León Hebreo, otros tratados, como Il Raverta, el Ragionamento d'amore de Sansovino, el Diálogo della infinità di amore de Tulia de Aragón o el Specchio d'amore de Gottifredi, aunque menos conocidos en nuestro país, sí estuvieron en boga en Italia (Aldomá 1998, Pozzi 1980). 
puesto que algunos jóvenes, mal aconsejados, aman a mujeres lascivas e infames, mercaderes de sus cuerpos:

Piacemi adunque che il nostro Giovane se innamori, ma in tal guisa, come diceva il detto signor mio padre, che non vi perda il cervello: cosa che io ho veduta avenire molte fiate a que' mal consigliati giovani che, accecati da non so che mi dire, si sono dati ad amare donne lascive ed infami le quali, gittatosi l'onore dopo le spalle, hanno isposti i corpi loro a vile e disonesto guadagno (Cinzio 1989: 78).

Mujeres que se erigen en ruina de los hombres, Caribdis portadoras de sus desgracias:

Perché si puote verissimamente dire che tali donne sono edifici di tutti i mali e ruina di tutti i buoni costumi, soffocatrici d'ogni virtù, destatrici di tutti i vizi, turbatrici della pace, origini delle sedizioni, ministre delle guerre, più voraci delle Arpie e delle Cariddi. Onde non senza cagione disse Orazio a giovane così malamente innamorato: 'Oh quanta è quella Cariddi, misero te, che ti travaglia, quando saresti tu degno di miglior fiamma!' Ed oltre a ciò, sono tali donne (se si possono dir donne) più frodolenti che le volpi, più crudeli che le tigri e più velenose che le serpi (1989: 78).

Concluye el autor que tal apetito bestial no puede ser llamado amor y que el joven deberá abstenerse y alejarse de las meretrices, como ya había indicado Platón:

E tali passioni non si deono nominare col santissimo nome di amore, ma si deono piuttosto chiamare furori insani ed appetiti bestiali, degni d'infinito biasimo. Da queste sozze fiamme e disoneste voglio che si astenga in tutto il nostro Giovane, e segua il precetto di Platone, che comandò che gli uomini della sua città si astenessero dalle meretrici, accioché il seme umano non si donasse a disonesto ed impudico luogo (1989: 78).

Tras la tajante prohibición, el Discorso prosigue con las empresas, el duelo por amor y el tipo de composiciones poéticas amorosas que el amado realiza para la mujer. En las indicaciones del autor recogemos tópicos petrarquistas conocidos de la lírica renacentista, entre los que sobresale la especial dedicación a la descripto puellae. Las indicaciones del Discorso concuerdan con los poemas amorosos presentes en las novelas ${ }^{9}$.

9 E, descrivendo il Giovane l'oro de' capelli della sua donna, onde gli avrà ordita Amore la rete e posti mille dolci lacci intorno al core, per tenervilo felicemente involto ed in cara servitù, vie più felice di qualunque libertà; il sereno di quella fronte, più chiara d'ogni quadro e fin diamante, ove ha veduto Amore tenere la maggior sede ed ivi spiegare la insegna sua; le ciglia di ebano finissimo, delle quali ha veduto il medesimo Amore farsi arco e mandargli al core le dorate quadrella per la 
En la Introducción de las Novelas, el público espera la respuesta al joven Flaminio, que representa a la juventud en general. Supuestamente las indicaciones del Discorso y las ideas de los Dialoghi deberían ser válidas en esos ejemplos. Tras la declaración de honestidad del Discorso, podría sorprender que las novelas o ejemplos de la Introducción estén dedicados al amor lascivo. En la Introducción, los argumentos de las novelas giran en torno a la cupiditas, amor lascivo, y son recurrentes a la hora de mostrar la maldad de las cortesanas para que los hombres del grupo, y los de la sociedad en general, se alejen de ellas. Entre el tono general de los ejemplos, solo uno de ellos muestra la parte bondadosa de una prostituta, Melina, que no quiso infectar al hombre que amaba.

El tema, como ya hemos dicho, es el amor lascivo, propio de las prostitutas o cortesanas, caracteres trazados como símbolo de la maldad humana, cúmulo de vicios entre los que destacan la lujuria, la avaricia e incluso la suciedad. El segundo carácter trazado es el del hombre joven, como el destinatario de los Dialoghi y del Discorso, que suele ser la víctima de la cortesana, quizá por su inmadurez y falta de sentido común.

Si nos atenemos al desenlace de los relatos, es posible establecer una clasificación en dos tipos: por un lado, los ejemplos en los que la prostituta con sus artimañas vence al pobre joven incauto, es decir, muestra de las opiniones de Fabio, el anciano; y, por otro, aquellos en los que el hombre logra derrotar a la pérfida cortesana mediante su astucia, muestra de los argumentos del joven Poncio. Tal distribución forma una estructura de contraste o de oposición de manera que, tras un relato en el que se exhiba la victoria femenina, el siguiente mostrará el modo de vencer a la mujer. De esta manera, a las maldades de Phrines y Caliena relatadas por Fabio, donde se comprueba el trágico final de quien acude a esas mujeres, les sigue la historia de Vico, en la que Poncio pretende demostrar que es posible librarse de sus artimañas con la astucia de un hombre sabio.

La reacción del auditorio tras oír los ejemplos es decididamente relevante: vitupera la maldad de las cortesanas, aunque hay quien opina que no todas llegan a esos extremos en el daño. Para demostrar que el hombre sabio puede librarse de sus maldades, la novela sucesiva permite descubrir que él sale airoso y la que resulta burlada es la cortesana. En los casos del triunfo moral del hombre, siempre hay quien considera, como Fabio o Aulo, que este tipo de novelas da pie a buscar la compañía de esas mujeres. El avance narrativo se produce, en definitiva,

luce di quegli occhi, vie più di tutte le stelle fiammeggianti; i gigli e le rose di quelle guancie, fra le quali egli ha veduta la istessa bellezza dolcemente scherzare; la porpora delle vermiglie labbra che sembran due preziosissimi rubini; e que' denti che avanzano le orientali perle; il collo, che fa colonna alle suddette bellezze, appo il quale perde l'alabastro; ed il petto, che vince l'avorio istesso, ornato di quelle sue acerbette pome che, malgrado della villana (1989: 85). 
gracias a los comentarios del auditorio masculino que, atento, corrobora, aplaude o censura lo que ha oído.

Omitimos el estudio detallado de los argumentos y desenlaces señalados por Aldomà (1998) para recordar solamente que las cortesanas pueden ser fratricidas para obtener al caballero que desean (ej. 1); dominan y arruinan a los hombres utilizando varias artimañas, desde fingir la propia muerte (ej. 3); engañan en el juego (ej. 5), hasta tramar venganzas (ej. 8); además, se muestran avariciosas (ejs. 2, 6 y 7), reincidentes (ej. 4) y lujuriosas (ejs. 1 y 9). En el carácter negativo de las cortesanas, trazado en los distintos ejemplos, sorprende el último relato de la Introducción, la historia de Lucio y Melina contada por Lucio, relato en el que, como decimos, destaca la bondad de la protagonista.

El ejemplo que cierra los casos de amores lascivos y cortesanas difiere de los demás en la protagonista, excepcionalmente buena entre las de su profesión, rasgo explicado básicamente por las circunstancias de su vida: se ha visto obligada a prostituirse y está arrepentida, mientras que el resto de las otras cortesanas que han desfilado a lo largo de los relatos ejercen su profesión por sus numerosos vicios, entre los que destacan la lujuria y la avaricia.

Tras la exposición de los ejemplos deshonestos, vemos cuán lejos queda la acepción del término cortesana propia del Cortesano, donde significaba meretriz honesta $^{10}$ (Romagnolo 2009, Zancan 1983), más cercano aquí en cambio al uso que le da Della Casa, quien las describe como vendedoras, «quale ha più fretta di spacciare la sua mercatanzia e di venderla a prezzo» ${ }^{11}$ :

Le meretrici quanto più di vergogna hanno, tanto sono da meno; perciocché l'officio loro è di compiacere per denari a chiunque le richiede; perciò lo avere vergogna, quantunque per sé cosa lodevole sia, men compiute nell'officio loro a fare ne le viene; laddove l'esserne senza, che di natura sua è biasimevole, da molto più divenire le fa (Della Casa, Tractatus de officiis, 1806: 271).

Giraldi en la Introducción de las Novelas elige como eje temático el amor lascivo, la cupiditas del amor obsceno, vituperado en sus escritos teóricos. Aprovechando la ausencia de las mujeres, los nobles en los Dialoghi abordan temas serios o las relaciones con las prostitutas. La exposición de temas de amores deshonestos

10 Romagnolo (2009: 153, n. 581); Masi (1996: 631).

11 Per che non si dee l'uomo ornare a guisa di femina, accioché l'ornamento non sia uno e la persona un altro, come io veggo fare ad alcuni che hanno i capelli e la barba inanellata col ferro caldo, e " 1 viso e la gola e le mani cotanto strebbiate e cotanto stropicciate che si disdirebbe ad ogni feminetta, anzi ad ogni meretrice, quale ha più fretta di spacciare la sua mercatanzia e di venderla a prezzo. Non si vuole né putire né olire, accioché il gentile non renda odore di poltroniero, né del maschio venga odore di femina o di meretrice; né perciò stimo io che alla tua età si disdichino alcuni odoruzzi semplici di acque stillate. (1977: 127) 
en el seno de las narrativa giraldiana ha suscitado diversas interpretaciones en aras de clarificar una supuesta contradicción; en la vía de esa neta diferencia entre las teorías expuestas en los Prólogos y la materia luego desarrollada, contradicción entre la moral que estos narradores predican en sus marcos narrativos, prólogos y sentencias, y el contenido de sus respectivas historias (Rabell 2003).

La inclusión del discurso forense en el complejo mundo de la literatura (Kibedi Vargas 1970, Cherchi 1983, Lasperas 1987 y Rabell 2001, 2003) ha reforzado la tesis del ejercicio retórico mediante una controversia, propia del mismo discurso forense o judicial. Para Rabell (2001) el discurso forense funciona como una máscara ambivalente detrás de la cual los narradores pueden desempeñar el papel de juez, fiscal o abogado defensor, ganando así la simpatía de una audiencia de ideologías heterogéneas. Cierto es que la génesis misma del exemplum está en la oratoria como prueba y que la controversia retórica (Cherchi 1983) es uno de los gérmenes de la novella como género en la misma Italia.

Aceptadas las variaciones retóricas o ejercicios de estilo, en términos actuales, nos gustaría añadir que se plantea también una cuestión de género y adecuación, como si de un acto de habla se tratara. Al componer los Dialoghi y, por ende, el resumen esbozado en el Discorso, Giraldi sigue unos cánones: estrictos y marcados moralmente en los tres Dialoghi y más ligeros en el Discorso puesto que en este se permite la inclusión de referencias familiares. Los Dialoghi siguen la estela de los tratados renacentistas de los humanistas, mientras que en el Discorso apresuradamente recoge las ideas importantes para una cuestión práctica, por lo que tiene que obviar las pesadas referencias a los filósofos. El Discorso, incluso perteneciendo al ámbito teórico, se presenta como un manual de uso práctico.

En las novelas, Giraldi recrea la materia que sabe que agradará al público y tal materia incluye la res lasciva, entroncando de esta manera en la línea temática de las novelas toscanas (Glenisson 1986) ${ }^{12}$. Podría argumentarse que las novelas de la Introducción, presentadas en principio como respuesta o ejemplos, o questio finita a la pregunta de un alumno joven a un maestro de la vida, el anciano Fabio, fueron escritas en su juventud y que tal distancia cronológica marcaría la diferencia con el resto. Sin embargo, Villari (2012) esboza magistralmente cuál es el proceso de gestación de las novelas de los Hecatommithi: a través de los comentarios de Cavalcanti y Piccolomini, que leyeron parte de la obra entre 1560 y 1563 , sabemos que el primer embrión estaba formado por setenta novelas y tres diálogos y que no hay mención alguna a las novelas o ejemplos de la Introducción ${ }^{13}$.

\footnotetext{
12 Al estudiar a Fortini se destaca la importancia de la línea erótica a la que pertenecerían Boccaccio, Sacheti, Sercambi, Sermini y Aretino, entre otros autores (Glenisson 1986: 14).

13 «Bartolomeo Cavalcanti non fa alcun cenno, nella sua lettera, alla presenza della lunga Introduzione contenente la condanna della prostituzione e la disquisizione sui risvolti etici e i vantaggi
} 
Descartada, pues, esa lectura en clave de obra juvenil, a diferencia de las novelas de Fortini ${ }^{14}$, no cabe sino aceptar que su inclusión fuera tardía y deliberada.

A pesar de la intención moralizante de Giraldi (Maestri 1971, Pieri 1978), no creemos que el autor temiera en ese momento, en 1565, las iras de las normas tridentinas; evidentemente las conocía, como se colige de las citas del duelo y los temas del matrimonio secreto, pero no parece preocuparle a él, como tampoco a los censores, la existencia de res lasciva. Dionisotti (1967) pone de relieve la necesidad de mitigar esa supuesta influencia tridentina en la literatura en los mismos años en que escritores publicaban y a la vez participaban en el Concilio (Dionisotti 1967). Cierto es que en el Índice de Parma y en otros opúsculos locales, como el de Tortona, se prohibieron los Hecatommithi en 1580 (Aldomá 1998, Righetti 1920, Rozzo 1991), pero no en otros, porque la literatura vulgar no era de interés para los censores, como había dicho muy bien Michele Ghisleri, futuro papa Pío V:

Col prohibire Orlando, Orlandino, Cento Novelle e simili altri libri faremmo pittosto ridere che altro, perchè simili libri non si leggono come cose a cui si abbia a credere, ma come favole e come si leggono anchi molti libri dei gentili come Lusciano, Lucrezio ed altri simili; nondimeno se ne parlerà nella congragazione dei teologi e poi a Sua Santità ed i reverendissimi (27 junio 1557) (Pasquini 1936: 36) (Prosperi 2003: 347) ${ }^{15}$.

El centro impresor más importante en Italia era Venecia y cualquier prohibición iba en contra de sus intereses comerciales (Grendler 1977). En España, a pesar de las indicaciones del traductor, los censores, como han explicado Cerrón (1996) y Vega (2014), tenían otras preocupaciones, como las herejías, que constituían un verdadero problema político. Mención especial merece el tratamiento abreviado del saco de Roma en la traducción española, porque el recuerdo de 1527 sí era una cuestión de gravedad tácitamente aceptada por el público y los impresores (Aldomá 1998: 482).

sociali del matrimonio... Esssa... non doveva essere, dunque, compressa nella parziale stesura che il letterato fiorentino ebbe modo di vedere». (Villari 2012: XVI)

14 Glenisson (1986) apunta a la creación temprana de parte de la obra, antes de 1540, para justificar el erotismo.

15 En 1562 el mismo cardenal Ghisleri, Inquisidor general y obispo en Mondoví, interviene en la censura del Decamerón indicando que se supriman las novelas contrarias a la religión (Rozzo 1991: 37). Righetti (1930), sin mencionar en ningún momento la traducción española, considera que una de las posibles causas de la inclusión de los Hecatommithi en los Î́ndices inquisitoriales radica precisamente en la novela de la Década I-2, la historia de Vana, que Gaytán sustituyó, tal como quedaba anunciado en el prólogo de la Primera Parte de las Cien Novelas. La novela italiana contiene asimismo algunos pasajes lascivos que ya fueron omitidos en la edición veneciana de 1574 (Rozzo 1991: 51). 
Giraldi vitupera el amor obsceno en el Discorso y en el marco de las novelas pero necesita esos mismos temas en los relatos porque sabe que el público los espera, y, en última instancia, se trata de una cuestión económica y de aceptación.

Para concluir, tras el estudio del Discorso intorno a quello che si conviene a giovane nobile e ben creato nel servire un gran principe compuesto en 1565, en relación con las novelas de la Introducción de la Primera Parte de las Cien Novelas, es decir, los Hecatommithi, publicados ese mismo año, observamos que se produce una aparente paradoja, explicada a nuestro entender tanto por cuestiones de estilo o retóricas, lo que se conoce como controversia, como por adecuación al género dialogístico o narrativo y, en el fondo, por una cuestión crematística o de expectación creada en el público. Es el lector o público quien de hecho configura no solo la pervivencia de un tipo de literatura sino también la materia (Boilève-Guerlet 1993: 99). Giraldi, polígrafo, juega con múltiples registros en su obra, mezclando los distintos géneros de la tradición para obtener éxito y salir así de la miseria y del destierro, del que tanto se lamenta. La modernidad del autor, más allá de la lectura moralizante y teórica, recae en saber mezclar a su antojo y, aparentemente, contradecirse solo en aras del éxito.

Recibido: 11/09/2014

Aceptado: 15/10/2014

\section{OBRAs CITADAS}

Aldomá García, Mireia (1993). «Los Hecatommithi de Giraldi Cinzio en España». En I. Arellano, C. Pinillos, M. Vitse y F. Serralta (coords.), Studia Aurea: actas del III Congreso de la AISO, III. Pamplona/Toulouse: Griso - Lemso, pp. 15-22. Consultado el 20 diciembre 2013, http://cvc.cervantes.es/literatura/aiso/pdf/03/ aiso_3_3_004.pdf

(1998). La recepción de la novella en España: los Hecatommithi de Giraldi Cinzio. Bellaterra: Publicaciones Universidad Autónoma de Barcelona. Microfilm.

Asor Rosa, Alberto (1979). La cultura della Controriforma. Bari: Laterza.

Beltrán Almería, Luis (1996). «La teoría de la novela de G. B Giraldi». Romanische Forschungen, 108 1/2, pp. 23-49.

BoILÈVe-Guerlet, Annick (1993). Le genre romanesque des théories de la Renaissance italienne aux réflexions du XVIIe siècle français. Santiago de Compostela: Publicaciones Universidad Santiago de Compostela.

BrusCagl, Riccardo (2013). «Un Modello bipolare per la novella del Cinquecento: Lasca e Giraldi» Sorbona. Consultado el 10-08-2014, http://f.hypotheses.org/wp-content/ blogs.dir/326/files/2014/02/RiccardoBruscagli.pdf

Castiglione, Baldassare (1994). El Cortesano. Mario Pozzi (ed). Madrid: Cátedra. (1981). Il Cortigiano. Amedeo Quandam (ed). Milán: Garzanti. 
Cerrón Puga, María Luisa (1998). «La censura literaria en el Index de Quiroga». En María Cruz García de Enterría y Alicia Cordón Mesa (eds.), Actas del IV Congreso Internacional de la AISO (Alcalá de Henares, 22-27 de julio de 1996), vol. 1. Alcalá de Henares: Servicio de Publicaciones de la UAH, pp. 409-418.

Della Casa, Giovanni (1977). Galateo. Claudio Manganelli (ed). Milán: Rizzoli. (1806). Tractatus de officiis inter potentiores et tenuiores amicos. Classici Italiani, 70. Milán: Società Tipografica.

Dionisotti, Carlo (1967). «La letteratura italiana nell'età del Concilio di Trento». En Geografia e storia della letteratura italiana. Turín: Einaudi, pp. 227-254.

Fenoglio, Chiara (2014). «Giraldi Cinzio pedagogo: la fortuna inglese dei Dialoghi della vita civile». Lettere Italiane, 66, 1, pp. 135-153.

GiRAldi Cinzio, Giovan Battista (2012). Gli Ecatommithi, 3 vol. Susanna Villari (ed). Roma: Salerno Editrice.

GLenIsson, François (1986). «Érotisme et obscenité dans les nouvelles de Pietro Fortini». En François Glenisson (coord.), Au pays d'Éros. Littérature et érotisme en Italie de la Renaissance à l'age baroque. París: Université de la Sorbonne Nouvelle, pp. 11-70.

GonzÁlez Ramírez, David (2011). «En el origen de la novela corta del Siglo de Oro: los novellieri en España». Arbor, 752, pp. 1221-1243.

Gorris CAmos, Rosanna (2008). «Jean Baptiste Giraldy Cynthien Gentilhomme Ferrarois : Il Cinthio in Francia». En Paolo Cherchi, Micaela Rinaldi e Mariangela Tempera (coord.), Giovan Battista Giraldi Cinzio gentiluomo ferrarese. (Atti del Convegno Tenuto a Ferrara, 1-2 dicembre 2005). Florencia: Olschki, pp. 77-129.

Grendler, Paul (1977). The Roman Inquisition and the Venetian press. Princeton: University Press.

KIBEDI VARGA, Aron (1970). Rhétorique et littérature. Études de structures classiques. París: Didier.

LASPÉRAS, Jean-Michel (1987). La nouvelle en Espagne au Siècle d'Or. Montpellier: Publications Université de Montpellier.

MAestri, Delmo (1971). «Gli Ecatommiti del Giraldi Cinzio. Una proposta di nuova lettura e interpretazione». Lettere Italiane, 23, 3, pp. 306-331.

(1975). «I dialoghi della vita civile negli ecatommiti di G.B. Giraldi Cinzio e nella trattatistica rinascimentale». Annali Istituto Universitario Orientale di Napoli. Sezione Romanza 17, 2, pp. 363-378.

(1991). «Potere e cortegiania nella seconda metà del Cinquecento: il Discorso sul servire un gran principe e uno Zibaldone pseudo-giraldiano». Schifanoia 12, pp. 91-103.

MAsI, Giorgio (1996). «La lirica e i trattati d'amore». En Storia della letteratura italiana, vol. IV: Il Primo Cinquecento. Roma: Salerno Editrice, 1996, pp. 595- 679 (631).

Mazzacurati, Giancarlo (1980). «Percosi dell'ideologia cortigiana». En Carlo Ossola (ed.). La corte e il cortigiano. Roma: Bulzoni, pp. 149-172.

Menéndez Pelayo, Marcelino (1943). Orígenes de la novela. Madrid: CSIC.

Paschini, Pio (1938). Letterati ed Indice nella Controriforma. Roma: Tipografia Vaticana.

PAtrizi, Giorgio (1990). «Giraldi Cinzio e la complicazione del racconto. Note per una lettura degli Hecatommithi». En VV. AA. La Novella italiana. Atti del Convegno di Caprarola. Roma: Salerno Editrice, pp. 885-899. 
PIEJEUs, Marie François (1975). «Narration et demonstration: le double apparat présentait dans les Ecatommiti di Giraldi Cizio». En Culture et societé. París: CNR, pp. 293310.

PIERI, Marzia (1978). «La strategia edificante degli Ecatommiti». Esperienze letterarie III, 3, pp. 43-74.

Pozzi, Mario (1980) (ed.). Trattati d'amore del Cinquecento. Bari: Laterza.

ProsPeri, Adriano (1996). Tribunali della coscienza. Turín: Einaudi.

RABELL, Carmen (2001). «Bajo la ley: la escritura de la novella española posterior al Concilio de Trento». Revista de Estudios Hispánicos 28, 1-2, pp. 309-325.

- (2003). Rewriting the Italian Novella in Counter-Reformation Spain. Woodbridge: Tamesis.

Romagnoli, Anna (2009). La donna nel Cortegiano nel contesto della tradizione. Tesis doctoral. Barcelona: Universidad de Barcelona. Consultada el 2-08-2014, http://www. tdx.cat/bitstream/handle/10803/1732/AR_TESI.pdf?sequence $=1$

Romera PINTOR, Irene (1997). «Un traducteur oublié de la Renaissance: Gabriel Chappuys». Cuadernos de Filología Francesa, 12, pp. 337-34.

(2013). «Giraldi Cinthio en su Carteggio: cum omnibus omnium horarum homo». Critica Letteraria, XLI, 2-3, 159-160, pp. 553-572.

Rozzo, Ugo (1991). «Gli Hecatommithi all’Indice». La Bibliofilia 1, pp. 21-51.

Truchado, Francisco (2014). Honesto y agradable entretenimiento de damas y galanes. Marco Federici (ed.). Roma: Nuova Cultura.

Vega Ramos, María José (2013). «La ficción ante el censor. La novella y los índices de libros prohibidos en Italia, Portugal y España (1559-1596)». En José Valentín Núñez (ed.), Ficciones en la ficción. Bellaterra: Universidad Autónoma de Barcelona, pp. 49-75.

Vian, Ana (2010) (ed.). Diálogos españoles del Renacimiento. Toledo: Almuzara.

ZANCAN, Marina (1983). «La donna nel Cortegiano di B. Castiglione. Le funzioni del femminile nell'immagine di corte». En Marina Zancan (ed.), Nel cerchio della luna. Figure di donna in alcuni testi del XVI secolo. Venecia: Marsilio, pp. 13-56. 


\section{(2)}

Didactismo, GÉNERo literario y LeCtor en Giraldi CinZio

RESUMEN: En este artículo se propone una revisión del Discorso intorno a quello che si conviene a giovane nobile e ben creato nel servire un gran principe en relación con los temas de las novelas de la Introducción de los Hecatommithi traducidos. Las propuestas morales de la teoría se contemplan desde la producción narrativa tardía de una parte de la obra. Como resultado, las novelas de Giraldi, mostradas habitualmente como ejemplo de la moral contrarreformista, son abordadas como una exigencia del público.

Palabras Clave: Giraldi Cinzio, Novella, Contrarreforma, Moralidad, Público, Literatura áurea.

\section{DIDACTISM, GENRE AND READER IN GIRALDI CINZIO}

ABSTRACT: This article aims at revising Discorso intorno a quello che si conviene a giovane nobile e ben creato nel servire un gran principe over the issues facing the tales of the Introducción of Hecatommithi's translation. The teaching regarding moral behavior is faced in the form of story-telling in a late part of the literary work. As a result, Giraldi's tales, usually displayed as an example of Counterreformation, are dealt with as coming from the reader's demand.

Keywords: Giraldi Cinzio, Novella, Reader, Morality, Counterreformation, Spanish Golden Age. 


\section{EDAD DE ORO}

Revista de Filología Hispánica XXXIII

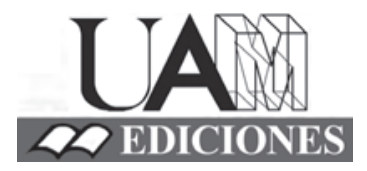




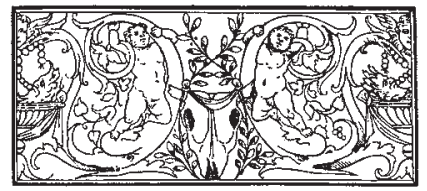

\section{Edad de Oro. Revista de Filología Hispánica}

ISSN: 0212-0429

Dirección:

Teodosio Fernández

Secretaría y edición:

José Ramón Trujillo

Coordinador del volumen XXXIII:

Rafael Bonilla Cerezo

Comité científico internacional:

Carlos Alvar (Univ. de Ginebra)

Ignacio Arellano (Univ. de Navarra)

Javier Blasco (Univ. de Valladolid)

Alberto Blecua (UAB)

Jean Canavaggio (Univ. de París X)

Laura Dolfi (Univ. de Turín)

Aurora Egido (Univ. de Zaragoza)

Víctor García de la Concha (RAE)

Luciano García Lorenzo (CSIC)

Joaquín González Cuenca (Univ. de Castilla-

La Mancha)

Agustín de La Granja (Univ. de Granada)

Begoña López Bueno (Univ. de Sevilla)

Michel Moner (Univ. de Toulouse III)

Joan Oleza (Univ. de Valencia)

Alfonso Rey (Univ. de Santiago)

Lina Rodríguez Cacho (Univ. de Salamanca)

Leonardo Romero Tobar (Univ. de Zaragoza)

Aldo Ruffinatto (Univ. de Turín)

Lía Schwartz (City University of New York)
Redacción y admisión de originales:

Teodosio Fernández

Edad de Oro

Departamento de Filología Española

Universidad Autónoma de Madrid

28049 Madrid (España)

Tfno.: +0034 914974090

correo: teodosio.fernandez@uam.es

Distribución, suscripción y venta:

Servicio de Publicaciones de la UAM

Universidad Autónoma de Madrid

28049 Madrid (España)

Intercambio de publicaciones:

Biblioteca de la Facultad de Filosofía y

Letras (UAM)

Universidad Autónoma de Madrid

28049 Madrid (España)

Han colaborado en este volumen:

Departamento de Filología Española (UAM)

Facultad de Filosofía y Letras (UAM)

Proyecto I+D FFI2013-41264-P La novela

corta del siglo XVII: estudio y edición (y II)

Edad de Oro se recoge en las siguientes bases de datos: SCOPUS, MLA Database, HLAS, Latindex, PIO-Periodical Content Index, ISOC, Dialnet, MIAR, ERIH, DICE, Sumaris CBUC, Ulrich's. Se encuentra evaluada en CIRC: A; INRECH: primer cuartil, posición 6 de 50; MIAR difusión ICDS live: 9.977; SCImago Journal \& Country Rank: H Index 2, SJR 0,101, Q4; RESH índice de impacto: 0.162; ERIH: A INT1; Carhus Plus+: B. 
Evangelina Rodríguez Cuadros (Universitat de València)

Novela cortesana, novela barroca, novela corta: de la incertidumbre al canon 9

Mita Valvassori (Universidad de Los Lagos)

El modelo narrativo del Decamerón en la Edad de Oro: una vieja historia .21

Antonio Gargano (Università degli Studi di Napoli Federico II)

«Difficile est proprie communia dicere»: el género de la novella entre

Boccaccio y Cervantes

Guillermo Carrascón (Università degli Studi di Torino)

Apuntes para un estudio de la presencia de Bandello en la

novela corta del siglo XVII

Leonardo Coppola (Università degli Studi «G. d'Annunzio» di Chieti-Pescara)

La proyección de Straparola en la novela española del Siglo de Oro desde una perspectiva editorial

Mireia Aldomà García

Didactismo, género literario y lector en Giraldi Cinzio

María Jesús Zamora (Universidad Autónoma de Madrid)

«...En tiempo menos discreto que el de agora, aunque de hombres más sabios, se

llamaban a las novelas cuentos». La novela corta y el cuento en el Siglo de Oro......109

Marcial Rubio (Università degli Studi «G. d'Annunzio» di Chieti-Pescara)

La contribución de Cervantes a la novela barroca: la ejemplaridad.

Pierre Darnis (Université Bordeaux Montaigne)

La fuerza de la sangre, La ilustre fregona $y$ Las dos doncellas: ¿tres tipos

folclóricos?

María Soledad Arredondo (Universidad Complutense de Madrid)

De La gitanilla a La sabia Flora malsabidilla. El género, el personaje

y el matrimonio

Antonella Gallo (Università degli Studi di Verona)

Fabulaciones en equívocos burlescos: la Chrónica del monstro imaginado (1615)

de Alonso de Ledesma y novela corta barroca

David González Ramírez (Universidad de Málaga)

El filósofo del aldea (1625) de Baltasar Mateo Velázquez: recepción textual

e hipótesis autorial.

JONATHAN BRADBURY (University of Exeter)

La narrativa breve en la miscelánea del siglo XVII... 
Cristina Castillo Martínez (Universidad de Jaén)

«La fuente del desengaño»: de las Noches de invierno de Eslava a la Tercera

Diana de Tejeda.

MARÍA Zerari (Université Paris-Sorbonne, CLEA)

Furor in fabula: La cruel aragonesa de Castillo Solórzano (o de la dama monstruo).. 241

Giulia Giorgi (Università degli Studi di Ferrara)

Alonso de Castillo Solórzano reescritor de sí mismo: algunas notas sobre los

Escarmientos de amor moralizados y el Lisardo enamorado .257

Angela Fabris (Alpen-Adria-Universität Klagenfurt)

El diálogo con el público y los espacios reales y de maravilla en

Casos prodigiosos y cueva encantada de Juan de Piña 267

María Rocío LePe García (IES San Sebastián, Huelva)

La traducción inglesa de Hipólito y Aminta: una adaptación

con fines comerciales 281

Andrea Bresadola (Università degli Studi di Udine)

La novela española en la Italia del siglo XVII: el caso de Il Feniso

de Francisco de Quintana.

José Teruel (Universidad Autónoma de Madrid)

El triunfo del Desengaño. Marco y desengaño postrero de la Parte segunda

del Sarao y entretenimiento honesto, de María de Zayas

Nieves Romero-Díaz (Mount Holyoke College)

Lecturas alternativas en la Novela del fin bueno en mal principio

de doña Ana Francisca Abarca de Bolea....

Shifra Armon (University of Florida)

Compromiso y distanciamiento en La Venus de Ferrara

de Mariana de Carvajal Saavedra

Mechthild Albert (Rheinische Friedrich-Wilhelms-Universität Bonn)

Las "noches": un subgénero novelístico en perspectiva comparada.... .365

Fernando Copello Jouanchin (Université du Maine, Le Mans)

El mueble en la novela corta del Siglo de Oro: algunas reflexiones

en torno a la cama

Ilaria Resta (Università del Salento):

De la novella al entremés pasando por la novela corta: reescrituras del cuento

La gara delle tre mogli del Cieco di Ferrara. 